\title{
A Parábola como instrumento linguístico mediador na pedagogia de Jesus acerca do Reino
}

\author{
La Parábola como instrumento lingüístico mediador en la \\ pedagogía de Jesús acerca del Reino
}

\section{The Parable as a mediating linguistic instrument in Jesus' pedagogy of the Kingdom}

João Carlos Domingues Dos Santos Rodrigues ${ }^{1}$

\begin{abstract}
RESUMO: Este artigo tem por objetivo promover uma aproximação entre a prática pedagogia de Jesus, empregada em seu fazer teológico, especialmente nas 'Parábolas do Reino', e o Interacionismo Sociodiscursivo (ISD) proposto por Bronckart. Partindo do pressuposto vygotiskyano da linguagem como ordenadora do real e baktiniano, dos gêneros textuais como enunciados relativamente estáveis por meio dos quais interagimos com o mundo, podemos lançar nosso olhar para a atividade linguageira de Jesus como uma ação singular pela qual a tomada de consciência não é a descoberta de um objeto mental inacessível, mas a redescoberta, a recriação desse objeto psíquico em um novo contexto. A utilização de um gênero textual bastante presente na vida religiosa judaica (a parábola) para transmitir a notícia do Reino, compõem o cenário de produção e o enredo das quatro parábolas que analisaremos. As 'Parábolas do Reino', presentes no Evangelho segundo Marcos, serão nosso corpus de investigação a partir dos conceitos de atividade de linguagem, texto e discurso apresentados na obra de Bronckart (1999). Pretendemos, ao final deste artigo, promover uma aproximação entre o ISD e os Estudos Bíblicos, até então desconhecido a nós, ampliando não apenas a compreensão acerca do agir pedagógicos de Jesus, mas abrindo espaço para que esse mesmo agir possa se manter eficaz por todos aqueles que pretendem trilhar os passos de Jesus e ser seus imitadores.
\end{abstract}

Palavras Chave: Jesus. Parábolas. Pedagogia. ISD.

RESUMEN: Este artículo tiene por objetivo promover un acercamiento entre la práctica pedagogía de Jesús, empleada en su hacer teológico, especialmente en las 'Parábolas del Reino', y el Interaccionismo Sociodiscursivo (ISD) de Bronckart. A partir

\footnotetext{
${ }^{1}$ Mestrando do PPGEL- Programa de Pós-Graduação em Estudos da Linguagem, Universidade Estadual de Londrina. E-mail joannescarlus@hotmail.com
} 
de los presupuestos vygotiskyano, del lenguaje como ordenadora de lo real, y baktiniano, de los géneros textuales como enunciados relativamente estables y por medio de los cuales interactuamos con el mundo, observamos las expresiones de Jesús no como una acción singular en que se realiza la toma de consciencia de un objeto mental inaccesible, sino como el redescubrimiento, la recreación de ese objeto psíquico en un nuevo contexto. La utilización de un género textual bastante presente en la vida religiosa judaica (la parábola) para transmitir la noticia del Reino, componen el escenario de producción y el enredo de las cuatro parábolas que analizaremos. Las "Parábolas del Reino", presentes en el Evangelio según Marcos, serán nuestro corpus de investigación a partir de los conceptos de actividad del lenguaje, texto y discurso de Bronckart (1999). En el final de este artículo, pretendemos, promover una aproximación entre el ISD y los Estudios Bíblicos, hasta entonces desconocido por nosotros, ampliando no solo la comprensión acerca de los actos pedagógicos de Jesús, sino abriendo espacio para que ese mismo actuar pueda mantenerse eficaz para todos aquellos que pretenden recorrer los pasos de Jesús y ser sus imitadores.

Palabras Clave: Jesus. Parábolas. Pedagogia. ISD.

ABSTRACT: The aim of this article is to promote an approximation between the pedagogy of Jesus, used in his theological work, especially in the 'Parables of the Kingdom' and Bronckart's Sociodiscursive Interactionism (ISD). From the vygotiskyano, the language-ordering of the real, and Bakhtinian presuppositions, of the textual genres as relatively stable statements, and in May of which we interact with the world, we observe that already Jesus, in his 'professional act', made use of these presuppositions, same ones that are on the bases of the ISD. The appreciation of the peculiar way in which the countrymen of Jesus saw and understood the world, as well as the use of a textual genre quite present in the Jewish religious life (the parable) to convey the news of the Kingdom, compose the scenario of production and the plot of the four parables we will analyze. The 'Parables of the Kingdom', present in the Gospel according to Mark, will be our corpus of inquiry, as well as Bronckart's 'Activity of language, text and speech'. We intend, at the end of this article, to promote a rapprochement between ISD and Biblical Studies, hitherto unknown to us, expanding not only the understanding of the pedagogical acts of Jesus, but opening space for this same action to be effective for all those who want to walk on the footsteps of Jesus and be his imitators.

KEYWORDS: Jesus. Parables. Pedagogy. ISD

\section{Introdução}

O objeto desta pesquisa são as quatro parábolas do Reino, presentes no capítulo 4 do Evangelho segundo Marcos - a saber: Parábola do Semeador (Mc 4,3-8; Mc 4,14-20); Parábola do Candeeiro (Mc 4,21-23); Parábola do Trabalhador do Campo (Mc 4,26-29) e Parábola da Semente de Mostarda Mc 
4,30-32. Esse olhar para estas parábolas de Jesus buscam uma reflexão acerca do método pedagógico e demais estratégias utilizadas por Jesus em seu "fazer teológico", em sua "prática profissional" na Galileia, sobre o que viria a ser o "Reino de Deus". (BÍBLIA, 2002).

Seja em sua função de promotora do 'intercâmbio social', seja na função de 'ordenadora do real' (VYGOTSKY, 2002, p. 12-13), a linguagem nos parece ter sido utilizada por Jesus em todo seu potencial, visando a promover um amplo desenvolvimento em seus discípulos. E se é por meio da linguagem que o ser humano significa o mundo e estrutura o próprio pensamento (VYGOTSKY, 2002), nada mais plausível que em sua prática pedagógica Jesus tenha buscado um método que partisse do modo próprio como seus conterrâneos significavam o mundo para fazê-los apreender, compreender e disseminar sua mensagem.

Disto decorre nossa hipótese, segundo a qual Jesus utilizava um método que muito se aproxima daquele da Teoria do Letramento, se valendo de alguns princípios daquilo que hoje constitui o Interacionismo Sociodiscursivo (BRONCKART, 1999). Seu método e os princípios por Jesus adotados, valendose do gênero parábola, demonstrariam uma prática que visava fazer com que seus ouvintes - os "leitores" de seu "texto oral" - pudessem, de modo gradativo e bastante contextualizado, passarem de uma compressão superficial e literal sobre o "Reino de Deus", para uma compreensão aprofundada e transformadora (de si e da própria realidade).

Nosso percurso de análise passará por uma explicitação das características linguísticas e discursivas presentes no gênero "parábola"; além da apresentação e comentários acerca dos textos conhecidos como "Parábolas do Reino", aquelas do capítulo 4 de Marcos, segundo a tradução da Bíblia da CNBB. Na sequência, apresentaremos o contexto histórico e cultural no qual Jesus e seus ouvintes estavam inseridos e que influenciaram tanto a prática de Jesus quanto a apropriação do texto. Por último, demonstraremos como o próprio Jesus compreendia e utilizava seu método, fazendo relações com os princípios do Interacionismo Sociodiscursivo (ISD) na prática de Letramento, 
que o auxiliaram a promover a passagem de uma "leitura" 'parafrástica' para uma 'polissêmica' acerca do conceito 'Reino de Deus'.

\section{Objeto da Análise - Parábolas do Reino em Marcos}

A palavra parábola vem do grego parabolé (параßо入n் - para= à margem, ao lado de + ballein= verbo arremessar, jogar) e significa "comparação" ou "uma história que conta outra história". Em hebraico, a palavra utilizada para parábola é mashal (משל) e diz respeito a um gênero literário utilizado pelos hebreus em ensinamentos que objetivavam 'a melhoria da conduta das pessoas' e falar de trechos das Escrituras 'aparentemente de significado mais obscuro' (GIGLIO, 2012).

No contexto histórico em que Jesus vivia, as parábolas eram bastante utilizadas pelos rabinos, os mestres, no ensino do Talmud, e mesmo tendo o caráter de 'comparação', eram entendidas como importante ferramenta de questionamento, pois ao mesmo tempo em que comentavam e explicavam verdades de fé mais abstratas, mantinham o texto aberto a interpretações (GIGLIO, 2012). Esse caráter aberto da parábola foi fortemente aproveitado por Jesus em seus ensinamentos, sendo algo que ele deixa transparecer em algumas expressões suas: "Se alguém tem ouvidos para ouvir, que ouça" (Mc 4,23); "Desse modo, eles olham sem ver, escutam sem compreender" (Mc 4,12). (BÍBLIA, 2002).

Paul Ricoeur, em sua obra "A metáfora viva", fala um pouco sobre esse caráter não tão declarativo da 'comparação' em relação à 'metáfora', afirmando que a metáfora, em geral, diz o 'ser', já a comparação diz o 'ser como'; a comparação "não se limita a dizer que isto é aquilo" e por esse motivo pode-se dizer que "a comparação é uma metáfora desenvolvida" (RICOEUR, 2000, p. 47-46).

Citando Aristóteles no Primeiro Livro de "A Retórica", Paul Ricoeur (2000, p. 44) apresenta uma dupla divisão da parábola, "que consiste na ilustração pelo exemplo", de modo que esse exemplo pode ser um exemplo histórico 
(efetivo) ou um exemplo fictício (como as fábulas de Esopo). No caso de Jesus, especificamente sobre as parábolas do Reino, é possível dizer que elas se enquadrariam em exemplos históricos (efetivos), pois são construídas a partir de fatos percebidos como verossímeis por seus ouvintes, algo que o evangelista Marcos faz questão de frisar: "ele (Jesus) Ihes anunciava a palavra, conforme eram capazes de compreender" (Mc 4,33) . (BÍBLIA, 2002).

Segundo Borges Arantes (2006, p. 105-112), em linhas gerais, uma parábola, seja ela produzida e difundida oralmente ou graficamente, é organizada em quatro momentos: Introdução: que propõe um resumo ou anúncio do tema a ser tratado; Cenário, contexto: diz respeito à localização das personagens no tempo e no espaço; Trama: abarcando o desenvolvimento da história, sua complicação e posterior resolução; Comentário, avaliação ou explicação são elementos que podem aparecer posteriormente à resolução/conclusão da história. Tal estruturação corresponderia àquilo que Bronckart, apoiando-se em Jean-Michel Adam, chama de "Sequência Narrativa" (BRONCKART, 1999, p. 219-222).

No que diz respeito à "atitude comunicativa" na produção de uma parábola, ela pode mesclar o mundo discursivo do narrar e o do expor ${ }^{2}$, porém, com uma predominância para o mundo narrar. O mundo discursivo da ordem do narrar apresenta uma "atitude comunicativa" em 'disjunção' ao mundo ordinário da situação de produção; por sua vez o mundo discursivo da ordem do expor é o que se coloca em 'conjunção' com o mundo ordinário da situação

\footnotetext{
2 Bronckart (1999, p. 150-164) afirma que no processo de semiotização do mundo, o agente, em sua 'atitude comunicativa', pode recorrer a dois 'arquétipos psicológicos' que correspondem a dois mundos discursivos: o mundo do narrar e o mundo do expor. O mundo discursivo do narrar é aquele que se encontra em 'disjunção' ao mundo ordinário da situação de produção, abarcando gêneros textuais como o romance, a fábula, o conto, a parábola dentre outros, requerendo do agente produtor a ancoragem espaço-temporal do discurso. 0 mundo discursivo do expor é aquele que se encontra em 'conjunção' com o mundo ordinário da situação de produção, motivo pelo qual o discurso não necessita de uma ancoragem espaço-temporal, abrangendo gêneros textuais como o artigo científico, a resenha, o ensaio e etc. Com relação ao 'ato de produção', à 'situação de produção', os mundos do narrar e do expor podem ser/estar em implicação ou em autonomia. O discurso é/está implicado quando é formado por recursos que marcam a interação, quando o agente produtor interage diretamente com seu destinatário. Contrariamente a isto, o discurso em autonomia ocorre quando não existem as marcas de interação entre o agente produtor e seu destinatário.
} 
de produção (NASCIMENTO33, 2018). Nas palavras de Bronckart, o mundo do narrar é "situado em 'outro lugar', mas esse outro lugar, entretanto, deve permanecer [...] como um mundo parecido, isto é, um mundo que deve poder ser avaliado ou interpretado pelos seres humanos que lerão o texto" (BRONCKART, 1999, p. 153); já no mundo do expor "(o conteúdo temático é interpretado) sempre à luz dos critérios de validade do mundo ordinário [...], podendo os elementos ficcionais expostos serem considerado, conforme o caso, como falsos, delirantes [...]" (BRONCKART, 1999, p. 154).

Geza Vermes (1996, p. 41-43) afirma que embora haja passagens bíblicas nas quais Jesus entra em confronto com ilustres fariseus, escribas e saduceus, não existem provas concretas que ele tenha recebido uma formação especializada. Todavia, é perceptível que os ensinamentos de Jesus, muito voltados à prática das Escrituras, valendo-se de parábolas, advertências proféticas e palavras sapiensiais, o faziam um pregador com estilo diferente daqueles de sua época, que se preocupavam em investigações teóricas da doutrina. Associando Deus à realidade em que vivia, tal como faziam os profetas, os sábios e os rabinos, "Deus era concebido e exposto por Jesus, não em termos filosóficos ou teológicos, mas numa linguagem existencial" (VERMES, 1996, p. 44).

O Reino é considerado o cerne dos ensinamentos de Jesus (VERMES, 1996, p. 45), o fim teleológico de seus ensinamentos, de sua prática profissional. Neste momento apresentaremos e analisaremos as quatro Parábolas do Reino, no Evangelho segundo Marcos, que compõem nosso objeto de pesquisa:

1a) Parábola do Semeador (Mc 4,3-9) - retrata a atividade de um semeador e a relação entre as sementes que ele lança e os diferentes solos em que elas caem:

Ouvi: Saiu o semeador a semear. Enquanto lançava a semente, uma parte caiu à beira do caminho, e vieram as aves e a comeram. Outra

\footnotetext{
${ }^{3}$ Elvira Lopes Nascimento. Gêneros Textuais do PPGEL. Londrina, UEL. Notas de aula da disciplina: de 15/03/2018 à 12/07/2018.
} 
parte caiu no pedregulho, onde não havia muita terra; o grão germinou logo, porque a terra não era profunda; mas, assim que o sol despontou, queimou-se e, como não tivesse raiz, secou. Outra parte caiu entre os espinhos; estes cresceram, sufocaram-na e o grão não deu fruto. Outra caiu em terra boa e deu fruto, cresceu e desenvolveu-se; um grão rendeu trinta, outro sessenta e outro cem. E dizia: Quem tem ouvidos para ouvir, ouça!

2a) Parábola do Candeeiro (Mc 4,21-25) - fala sobre a relação de funcionalidade entre luz e escuridão (BÍBLIA, 2002):

Dizia-lhes ainda: Traz-se porventura a candeia para ser colocada debaixo do alqueire ou debaixo da cama? Não é para ser posta no candeeiro? Porque nada há oculto que não deva ser descoberto, nada secreto que não deva ser publicado. Se alguém tem ouvidos para ouvir, que ouça. Ele prosseguiu: Atendei ao que ouvis: com a medida com que medirdes, vos medirão a vós, e ainda se vos acrescentará. Pois, ao que tem, se lhe dará; e ao que não tem, se Ihe tirará até o que tem.

3a) Parábola do Trabalhador do Campo (Mc 4,26-29) - trata da relação entre o trabalhador do campo, o próprio campo e os frutos de seu trabalho (BÍBLIA, 2002):

Dizia também: O Reino de Deus é como um homem que lança a semente à terra. Dorme, levanta-se, de noite e de dia, e a semente brota e cresce, sem ele o perceber. Pois a terra por si mesma produz, primeiro a planta, depois a espiga e, por último, o grão abundante na espiga. Quando o fruto amadurece, ele mete-lhe a foice, porque é chegada a colheita.

4a) Parábola da Semente de Mostarda (Mc 4,30-32) - discorre sobre 0 vínculo paradoxal entre o pé de mostarda e sua semente (BÍBLIA, 2002):

Dizia ele: A quem compararemos o Reino de Deus? Ou com que parábola o representaremos? É como o grão de mostarda que, quando é semeado, é a menor de todas as sementes. Mas, depois de semeado, cresce, torna-se maior que todas as hortaliças e estende de tal modo os seus ramos, que as aves do céu podem abrigar-se à sua sombra.

As parábolas de Jesus sobre o Reino, no evangelho segundo Marcos, evidenciam a dupla possibilidade de 'atitude comunicativa' na produção de uma parábola. Isto é identificável pelo fato de que a parábola do 'Semeador' e a do 
'Trabalhado do Campo' são construídas num mundo ficcional à parte para transmitir a mensagem pretendida; por sua vez, a parábola do "Candeeiro" e da "Semente de Mostarda" se utilizam de critérios de verdade ou falsidade para propor a aceitação da mensagem exposta. Destaca-se o fato de que tanto as parábolas que apresentam o discurso da ordem do expor quanto da ordem do narrar estão em 'autonomia' com relação à situação de produção, pois não existem unidades linguísticas que façam referência ao agente produtor (Jesus) em nenhuma das quatro parábolas, estando elas em relação de independência para com esse agente.

Apesar da predominância da tipologia linguística de uma sequência narrativa ${ }^{4}$ na estrutura do gênero parábola, e levando-se em conta que "embora o processo de empréstimo (dos gêneros textuais ao intertexto) inspirese, necessariamente, em modelos existentes, quase nunca acaba em uma cópia integral ou em reprodução exata de um exemplar desse modelo" (BRONCKART, 1999, p. 102), consideramos que Jesus, ao produzir a parábola do 'Semeador' e a do 'Trabalhado do Campo', pertencentes à ordem de narrar, seguiu a tipologia linguística de uma sequência narrativa:

Quadro 1- Tipologia linguística e sequência narrativa.

\begin{tabular}{|l|l|l|}
\hline $\begin{array}{l}\text { Composta por três } \\
\text { unidades básicas } \\
\text { (BRONCKART, } \\
\text { 1999, p. 220) }\end{array}$ & Parábola do Semeador & $\begin{array}{l}\text { Parábola do Trabalhado do } \\
\text { Campo }\end{array}$ \\
\hline $\begin{array}{l}\text { INÍCIO (situação } \\
\text { inicial) }\end{array}$ & Saiu o semeador a semear. & $\begin{array}{l}\text { O Reino de Deus é como } \\
\text { um homem que lança a } \\
\text { semente à terra. }\end{array}$ \\
\hline $\begin{array}{l}\text { MEIO } \\
\text { (transformação) }\end{array}$ & $\begin{array}{l}\text { Enquanto lançava a semente, uma parte } \\
\text { eaiu à beira do caminho, e vieram as aves } \\
\text { e a comeram. Outra parte caiu no } \\
\text { pedregulho, onde não havia muita terra; o } \\
\text { grão germinou logo, porque a terra não } \\
\text { era profunda; mas, assim que o sol }\end{array}$ & $\begin{array}{l}\text { Dorme, levanta-se, de noite } \\
\text { e de dia, emente brota } \\
\text { perceber. Pois a terra por si } \\
\text { mesma produz, primeiro a } \\
\text { planta, depois a espiga e, }\end{array}$ \\
\hline
\end{tabular}

\footnotetext{
${ }^{4}$ Baseado no pensamento de Jean-Michel Adam, Bronckart (1999, p. 218) afirma existirem modelos abstratos que produtores e receptores dispõem, auxiliando-os na construção e compreensão dos textos. Estes modelos, protótipos, se materializam em seis tipos linguísticos: sequência narrativa; sequência descritiva; sequência argumentativa; sequência explicativa; sequência dialogal; sequência injuntiva.
} 


\begin{tabular}{|l|l|l|}
\hline & $\begin{array}{l}\text { despontou, queimou-se e, como não } \\
\text { tivesse raiz, secou. Outra parte caiu entre } \\
\text { os espinhos; estes cresceram, sufocaram- } \\
\text { na e grão não deu fruto. Outra caiu em } \\
\text { terra boa e deu fruto, cresceu e } \\
\text { desenvolveu-se; um grão rendeu trinta, } \\
\text { outro sessenta e outro cem. }\end{array}$ & $\begin{array}{l}\text { por uano } \\
\text { abundante na espiga. }\end{array}$ \\
\hline FIM (situação final) & Quem tem ouvidos para ouvir, ouça! & $\begin{array}{l}\text { Quando o fruto amadurece, } \\
\text { ele mete-lhe a foice, } \\
\text { porque é chegada a } \\
\text { colheita. }\end{array}$ \\
\hline
\end{tabular}

Fonte: Autor.

Já ao produzir a parábola do 'Candeeiro' e a da 'Semente de Mostarda', vinculadas à ordem do expor, seguiu a tipologia linguística básica de uma sequência explicativa: 
Quadro 2 - Tipologia linguística básica e a sequência explicativa.

\begin{tabular}{|c|c|c|}
\hline $\begin{array}{l}\text { Composta por quatro } \\
\text { unidades } \\
\text { (BRONCKART, 1999, p.226- } \\
\text { 227) }\end{array}$ & Parábola do Candeeiro & $\begin{array}{l}\text { Parábola da Semente de } \\
\text { Mostarda }\end{array}$ \\
\hline $\begin{array}{l}\text { CONSTATAÇÃO (na qual se } \\
\text { introduz uma ação, } \\
\text { situação não contestável) }\end{array}$ & $\begin{array}{l}\text { Traz-se porventura a candeia } \\
\text { para ser colocada debaixo do } \\
\text { alqueire ou debaixo da cama? }\end{array}$ & $\begin{array}{l}\text { A quem compararemos } 0 \\
\text { Reino de Deus? }\end{array}$ \\
\hline $\begin{array}{l}\text { PROBLEMATIZAÇÃO } \\
\text { (explicitações da ordem do } \\
\text { porquê ou do como, } \\
\text { relacionadas a contradições } \\
\text { do enunciado) }\end{array}$ & $\begin{array}{l}\text { Não é para ser posta no } \\
\text { candeeiro? }\end{array}$ & $\begin{array}{l}\text { Ou com que parábola o } \\
\text { representaremos? }\end{array}$ \\
\hline $\begin{array}{l}\text { RESOLUÇÃO (introduz } \\
\text { informações } \\
\text { complementares, capaz de } \\
\text { resolver as contradições) }\end{array}$ & $\begin{array}{l}\text { Porque nada há oculto que não } \\
\text { deva ser descoberto, nada } \\
\text { secreto que não deva ser } \\
\text { publicado. }\end{array}$ & $\begin{array}{l}\text { É como o grão de mostarda } \\
\text { que, quando é semeado, é a } \\
\text { menor de todas as sementes. }\end{array}$ \\
\hline $\begin{array}{l}\text { CONCLUSÃO-AVALIAÇÃO } \\
\text { (reformula e/ou completa a } \\
\text { informação inicial) }\end{array}$ & $\begin{array}{l}\text { Se alguém tem ouvidos para } \\
\text { ouvir, que ouça. Ele prosseguiu: } \\
\text { Atendei ao que ouvis: com a } \\
\text { medida com que medirdes, vos } \\
\text { medirão a vós, e ainda se vos } \\
\text { acrescentará. Pois, ao que tem, } \\
\text { se lhe dará; e ao que não tem, } \\
\text { se lhe tirará até o que tem. }\end{array}$ & $\begin{array}{l}\text { Mas, depois de semeado, } \\
\text { cresce, torna-se maior que } \\
\text { todas as hortaliças e estende } \\
\text { de tal modo os seus ramos, } \\
\text { que as aves do céu podem } \\
\text { abrigar-se à sua sombra. }\end{array}$ \\
\hline
\end{tabular}

Fonte: Autor.

Essa constatação, a nosso ver, evidencia o fato de que esse instrumento psicolinguístico que é o gênero textual parábola, na medida da interação concreta do indivíduo (Jesus) com o meio (o povo da Galileia), não apenas se apropria do instrumento mediador elaborado pelas gerações anteriores (as parábolas usadas pelos rabinos no ensino do Talmud e das Escrituras), mas ele o altera segundo sua situação de uso (o ensino sobre o Reino), tal como fazem todos os usuários da língua (SCHNEUWLY, 2004, p. 23). 


\section{Os contextos históricos-cultural - situacional das Parábolas}

Anteriormente às quatro parábolas do Reino, o evangelista Marcos, nos Capítulo 3, versículo $7^{5}$ e Capítulo 4, versículo $1^{6}$, localiza geograficamente Jesus como ensinando uma grande multidão junto ao Mar da Galileia. Esta região é emblemática, já que sua infância se passou em Nazaré, que fica ao sul da Província da Galileia, região dos vales; e sua vida adulta em Cafarnaum, localizada ao norte do Mar da Galileia, a região das montanhas. O Mar da Galileia, ainda que assim seja chamado, na verdade é um grande lago alimentado pelo Rio Jordão, com 24 Km de comprimento, 14 de largura e 50 m de profundidade. Está a $45 \mathrm{Km}$ do Mar Mediterrâneo e a 100 Km de Jerusalém. Cercado por importantes cidades, dentre as quais: Genezaré, Betsaída, Tiberíades, Cafarnanum, Corazim e Magdala; banha uma fértil planície que, a época de Jesus, agrupava uma população estimada de 150 mil pessoas (FREYNE, 2018; THEISSEN; MERZ, 2004, p. 185-190).

A distância de Jerusalém fez da região da Galileia um lugar fértil para o surgimento de movimentos messiânicos, oposicionistas ao rei e com pretensões libertadoras, como foi o caso dos zelotes (ASLAN, 2018; THEISSEN; MERZ, 2004 , p. 195), e posteriormente do próprio Jesus. Em tal contexto cultural, discursos acerca das profecias referentes ao Messias, o sucessor do Rei Davi, e a consequente reinstauração de seu Reino, eram familiares (VERMES, 1996, p. 45-47). Todavia, diferentemente do discurso bélico e militarizado ao qual os galileus já estavam acostumados, a novidade trazida por Jesus foi a de um Messias e de um Reino com conotações proféticas, sociais e terapêuticas (físicas e espirituais), porém, em nada menos revolucionário (FREYNE, 1996, p. 51-54, 61-65; THEISSEN; MERZ, 2004, p. 195-199, 202-203; VERMES, 1996, p. 47-49).

\footnotetext{
5 "Jesus retirou-se com os seus discípulos para o mar, e seguia-o uma grande multidão, vinda da Galiléia" (Mc 3,7).

6 "Jesus pôs-se novamente a ensinar, à beira do mar, e aglomerou-se junto dele tão grande multidão, que ele teve de entrar numa barca, no mar, e toda a multidão ficou em terra na praia" (Mc 4,1).
} 
Economicamente, a Galileia destacava-se pelas atividades agrícolas, pastoris e pesqueiras, Jerusalém e algumas cidades mais ao sul, na Província da Judeia, eram fortemente urbanizadas (PIPOLLO, 1991, p. 40-41). Mas não apenas o modo de vida mais rural, com relação a outras regiões do povo de Israel, faziam deles um povo "diferente", provavelmente devido a seu contato mais aberto com relação a outros povos ${ }^{7}$, também sua dicção era diferente daquela dos de Jerusalém, falando um dialeto do aramaico ${ }^{8}$ - Reforçando essa ideia, Theissen e Merz (2004, p. 190) citam um texto do Talmud que faz referência à dificuldade que os habitantes daquela região tinham em falar sons mais guturais, fazendo com que houvesse a confusão na compreensão de quatro palavras em aramaico: hamâr= jumento; hamar= vinho; 'amar= lã; e immar $=$ cordeiro' 9 .

Essa situação de "marginalizados", por parte dos galileus, além de reforçar suas expectativas por uma transformação social, que encontravam no discurso e nas práticas de Jesus, também atraia outros grupos sociais que também se reconheciam em situação de exclusão e/ou esquecimento social, como é o caso das mulheres (viúvas ou prostitutas) e cobradores de impostos (Mt 9,10-13; Mc 2,15; LC 13,1-3; LC 15,1) (PIPOLLO, 1991, p. 41-42).

\section{A pedagogia de Jesus}

Concebendo um Reino que não deveria ser instaurado belicamente e no qual não haveria tronos, cortesãs, carros, espadas ou lanças, Jesus o apresentava figurativamente por meio das visões da paisagem, dos habitantes do campo, sua vida a beira mar e seus instrumentos de trabalho (VERMES, 1996, p. 49). Tal compreensão acerca de sua prática, do conteúdo dessa

\footnotetext{
7 Theissen e Merz (2004, p. 184, 190).

${ }^{8}$ É, ainda, admissível que alguns habitantes daquela região falassem a língua grega, inclusive Jesus, já que era uma língua bastante utilizada em transações comerciais (ZUURMOND, 1998, p. 53-54).

9 Também o Evangelho segundo Mateus faz menção a isso, quando uma pessoa na casa do Sumo Sacerdote (Mc 26,57) reconhece Simão Pedro como Galileu apenas por seu modo de falar: "os que ali estavam aproximaram-se de Pedro e disseram: Sim, tu és daqueles; teu modo de falar te dá a conhecer" (Mt 26,73).
} 
prática e de seus destinatários, nos faz conceber Jesus como adiantando praxiologicamente aquilo que mais tarde seria explicitado teoricamente por Paulo Freire:

\begin{abstract}
A leitura do mundo precede a leitura da palavra, daí que a posterior leitura desta não possa prescindir da continuidade da leitura daquele. Linguagem e realidade se prendem dinamicamente. A compreensão do texto a ser alcançada por sua leitura crítica implica a percepção das relações entre o texto e o contexto (FREIRE, 1992, p. 11-12).
\end{abstract}

A adoção de tal pedagogia, como o próprio Jesus sugere (Mc 4,9-12), tinha em vista mostrar que o Reino por ele proposto não se identificava com nada que existisse 'concretamente' neste mundo, apenas 'alegoricamente', 'metaforicamente', 'comparativamente'. Resguardada a mensagem aos membros do grupo, preservava o tom de mistério e curiosidade sobre o tema aos que ainda não faziam parte do grupo; mas também, aos iniciados, motivava o desejo de fazer real a proposta apresentada por meio das parábolas. Assim, ao mesmo tempo em que pareciam ensinamentos bobos, sem sentido e não hostis, aos de fora: "Desse modo, eles olham sem ver, escutam sem compreender, sem que se convertam e lhes seja perdoado" (Mc 4,12); eram especialmente adaptados às capacidades simbólicas e cognitivas de seus conterrâneos: "Era por meio de numerosas parábolas desse gênero que ele lhes anunciava a palavra, conforme eram capazes de compreender. E não thes falava, a não ser em parábolas" (Mc 4,33-34), criando uma zona de desenvolvimento proximal (VYGOTSKY; LURIA; LEONTIEV, 2010, p. 18, 112115).

Encaixando a prática do ensino dessas parábolas sobre o Reino, às demais ações de Jesus, sob a ótica de uma teoria do letramento, podemos dizer que os objetivos pretendidos eram dois: Em uma Dimensão Individual: Levar o indivíduo à autonomia e ao pleno uso de suas habilidades linguísticas (a compreensão sobre o Reino e as Escrituras); e em uma Dimensão Social: Promover a transformação das realidades à medida que amplia a compreensão 
dos indivíduos sobre si e sobre o mundo que o cerca (promover a instauração do Reino e uma tomada de decisão coerente, por parte de seus seguidores).

Vale aqui um adendo acerca do ouvir, da audição, para a cultura judaica de um modo geral. Como destaca Rochus Zuurmond (1998, p. 47-48), "a 'audição' da narração é, pois, o complemento necessário (o 'efeito') de uma história". [...] "Os que 'escutam' acabam pertencendo ao que é narrado (dabar), recebem um nome, isto é, identidade, vocação, missão. São integrados num conjunto, numa aliança, recebem uma incumbência"; deste modo, para um judeu, não ouvir não seria apenas um ato de desobediência ${ }^{10}$, mas um não fazer parte do grupo, não ser atingido pela história. Esta afirmação nos faz perceber que a transmissão oral da parábola não era apenas o meio de divulgação do gênero, mas parte integrante da mensagem, algo que é frisado pelo próprio Jesus como conclusão da parábola do Semeador: "Quem tem ouvidos para ouvir, ouça!" (Mc 4,9); e ao falar sobre os que não faziam parte do grupo e não aderiam às parábolas, diz: "eles olham sem ver, escutam sem compreender, sem que se convertam" (Mc 4,12). (BÍBLIA, 2002).

$\mathrm{Na}$ prática de leitura proposta por Jesus, o gênero literário parábola aparece como principal instrumento. Sua concepção de leitura, dentre as quatro apresentadas por Cosson (2014, p. 37-41), tinha por ênfase o 'contexto' - nela, a comunidade, o coletivo, a sociedade, a cultura, agem sempre como instâncias reguladoras da leitura; ler se torna sempre uma atividade social de uma comunidade discursiva. No caso específico das parábolas, que foram veiculadas de modo oral, os leitores são ouvintes, e a leitura-audição era mediada e regulada pela cultura do povo Galileu. Um exemplo concreto desse papel da comunidade (da cultura do grupo) como instância reguladora é destacado por Schottroff (2007, p. 92-93), que, baseado em descobertas arqueológicas, afirma que até o século I d.C. persistia a técnica de semear a terra apenas lançando as sementes sobre o solo, seja devido ao fato do pequeno tamanho

\footnotetext{
${ }^{10}$ Recordamos, aqui, o preceito deuteronômico do Shemá, dado por Deus ao povo judeu após a entrega das Tábuas da Lei: "Escuta Israel, o Senhor é nosso Deus, o Senhor é único" (Dt $6,4)$.
} 
das propriedades, seja devido à grande presença de rochas, tornando verossímil e compreensível a Parábola do Semeador (Mc 4,3-9).

Destarte, admite-se a modalidade oral não apenas como meio de difusão do texto, mas como elemento envolvente e enticante. Reconhece-se a parábola como instrumento de sua prática pedagógica. Assume-se uma compreensão de leitura que enfatiza o contexto do texto (da parábola). Quanto ao objeto da leitura-audição, por parte de Jesus, identificamos que esse não foi 'o texto' (o elemento linguístico materializado), nem mesmo 'o contexto' (a recepção do texto e os possíveis efeitos nos leitores), mas sim 'o intertexto'11: o vínculo cultural e afetivo entre autor e leitores, demonstrando $o$ interesse exclusivamente na transmissão da mensagem do modo mais simples e compreensível possível; o modo como o autor se apropria do gênero criando um estilo próprio; como seu estilo próprio se relacionava com sua prática e sua mensagem como um todo; as diversas relações que aquele texto fazia com outros textos já conhecidos por todos, promovendo uma releitura e ampliação de sentido desses outros textos.

Complementado pelo caráter adaptável e aberto dos gêneros textuais, no nosso caso, da parábola (SCHNEUWLY, 2004, p. 23), e pela cultural compreensão de envolvimento existencial promovido pela audição do texto oral (ZUURMOND, 1998, p. 47), a adoção do 'intertexto' como objeto da leituraaudição coaduna-se perfeitamente em uma prática de leitura que visa ir além do tradicional. Não havendo "discurso fechado em si [...]" (ORLANDI, 2005, p. 62), nem mesmo "um 'sentido em si"' (BAKHTIN, 1997, p. 387), a leitura do 'intertexto' como objeto assume a perspectiva de que "cada enunciado é um elo da cadeia muito complexa de outros enunciados" (BAKHTIN, 1997, p. 292), abrindo espaço para uma postura responsava - ativa do leitor, modificando, acrescentando, enriquecendo a si, ao próprio enunciado e a realidade na qual estes estão inseridos (BAKHTIN, 1997, p. 295, 298).

${ }^{11}$ Cosson (2014, p. 72-80), apresenta texto, contexto e intertexto como os três objetos da leitura que podem ser aproveitados pelo professor em sua prática de ensino. 
Neste contexto, o conteúdo temático (o tratamento exaustivo do objeto de sentido), devido à linguagem conotativa e aos demais recursos analógicos inerentes ao gênero parábola e próprios do estilo do autor, ganharia dimensões que seriam proporcionais às capacidades cognitivas dos leitores-ouvintes, extrapolando o sentido imediato e parafrástico do texto, assumindo características polissêmicas. Essa expansão do sentido daquilo que é/está sendo dito seria o objetivo pragmático (imediato) da ação pedagógica de Jesus, de sua "aula"; cada parábola comporia um "ato" nesta ação; o modo como cada parábola é estruturada e as reflexões promovidas seriam "etapas" desta ação (MACHADO, 2004).

Exemplos para as parábolas construídas num mundo ficcional à parte (mundo do narrar):

10) A 'Parábola do Semeador', que tem por conteúdo temático as relações do semeador com a terra e os frutos de seu trabalho, apresentaria várias interpretações: a) Tomando o Reino de Deus como a semente e a si próprio como o semeador, promoveria o questionamento do leitor-ouvinte sobre sua atuação em vista da concretização do Reino, se sua prática estaria ou não sendo produtiva; b) Assumindo a figura do solo no qual a semente é plantada, havia um questionamento sobre como esse leitor-ouvinte estaria recepcionando a mensagem apresentada por Jesus; c) Reconhecendo a si mesmo como a semente, o leitor-ouvinte poderia se questionar sobre como estaria sua vivência da mensagem do Reino. (BÍBLIA, 2002).

$2^{\circ}$ ) Na 'Parábola do Trabalhador do Campo', que tematiza a atuação do trabalhador no desenvolvimento da planta, ao focalizar a própria atividade do trabalhador, o leitor-ouvinte poderia se questionar sobre a postura de humildade que se deve assumir na atividade de anúncio do Reino; sobre a atuação misericordiosa e autônoma de Deus que, independente dos agentes, é quem faz as sementes darem frutos. Mas se o foco se voltasse ao processo como um todo, poderia motivar a percepção de que nada acontece por acaso, nem mesmo a ação divina se dá toda de uma única vez. 
Exemplos para as parábolas que se utilizam de critérios de verdade ou falsidade (mundo do expor) (BÍBLIA, 2002):

10) A 'Parábola do Candeeiro', que tem por conteúdo temático a funcionalidade da luz, promove um questionamento acerca das atitudes individuais daqueles que se propõem fazer parte do Reino, fazendo com que cada um reflita sobre quais são suas luzes e quais são suas trevas, não colocando a si nem os outros acima ou abaixo daquilo que realmente são.

20) Para a 'Parábola da Semente de Mostarda', que traz o paradoxo entre a semente da mostarda e a planta já formada, caso focalizasse o papel da semente na história, levaria o leitor-ouvinte a uma reflexão sobre o potencial transformador das próprias ações e a responsabilidade por elas, por menores que sejam; em sendo o foco a planta já formada, o questionamento poderia recair sobre quem pode ou não fazer parte do Reino, ou se esse Reino está a serviço de suas lideranças ou se a atividade das lideranças é estar a serviço.

\section{Considerações Finais}

Ao final de nossa reflexão pudemos demonstrar a possível articulação entre os pressupostos das práticas de Letramento e o Interacionismo Sociodiscursivo. A prática discursiva de Jesus criava zonas de desenvolvimento proximal por meio das Parábolas do Reino, proporcionando não apenas a facilitação da aprendizagem, mas valendo-se do potencial da linguagem para apresentar uma visão de Reino de Deus que se colocasse em contínuo processo de ampliação conceitual.

Identificamos que a lógica que ordena a sequência desses 'atos', na prática de Jesus ao contar suas parábolas do Reino, se aproxima da lógica organizacional de uma sequência didática. Apontamos para a importância de futuras pesquisas que numa perspectiva mais ampla e contínua das práticas de ensinamento adotadas por Jesus em diferentes gêneros textuais (além das parábolas), nos ajudariam a compreender a sua atividade de linguagem sob o ângulo de como ele representa sua ação nos e pelos textos. 


\section{Referências}

ARANTES, Marilza Borges. A argumentação nos gêneros fábula, parábola e apólogo. 2006. Dissertação (Mestrado em Linguística) - Instituto de Letras e Linguística, Universidade Federal de Uberlândia, Uberlândia, 2006.

ASLAN, Reza. Zelota: a vida e a época de Jesus de Nazaré. 2018. São Paulo: Zahar. Disponível em:

https://books.google.com.br/books?id=Xa3vAQAAQBAJ\&pg=PT90\&dq=mar+da +galiléia\&hl=pt-BR\&sa $=X \& v e d=0 a h U K E w i B v_{-}-$

4narcAhWCrVkKHd21Dyw4FBDoAQhXMAk\#v=onepage\&q=galileia\&f=false.

Acesso em: 20 jul. 2018

BAKHTIN, Mikhail. Estética da criação verbal. São Paulo: Martins Fontes, 1997.

BRONCKART, Jean-Paul. Atividade de linguagem, texto e discurso: por um interacionismo sociodiscursivo. São Paulo: Educ, 1999.

BÍBLIA. Português. Bíblia sagrada. 2. ed. São Paulo: Loyola, 2002.

COSSON, Rildo. Círculo de leitura e letramento literário. São Paulo: Contexto, 2014.

FREIRE, Paulo. $A$ importância do ato de ler. em três artigos que se completam. São Paulo: Cortez: Autores Associados, 1992.

FREYNE, Sean. A Galiléia, Jesus e os evangelhos. São Paulo: Loyola, 1996.

FREYNE, Sean. Jesus, um judeu da Galiléia: nova leitura da história de Jesus. São Paulo: Paulus. 2018. Disponível em:

https://books.google.com.br/books?id=n_25DAAAQBAJ\&pg=PT55\&dq=galiléia\& $\mathrm{hl}=\mathrm{pt}-$

BR\&sa =X\&ved=0ahUKEwiP9LGJnqrcAhXGpFkKHWc7AXAQ6AEIMzAC\#v=onepa ge\&q\&f=false. Acesso em: 19 jul. 2018.

GIGLIO, Auro Del. Iniciação ao Talmud. 2012. Disponível em:

https://books.google.com.br/books?id=tQNDDwAAQBAJ\&pg=PT84\&lpg=PT84\& $\mathrm{dq}=$ "agadá"+rabino\&source=bl\&ots=uPE1y2jNn1\&sig=BSRX4RE1k-

3bhPpL3wONAH1-T6g\&hl=pt-

BR\&sa=X\&ved=2ahUKEwj6_5WFz6bcAhVRx1kKHb8bBusQ6AEwAXoECAMQAQ\# $\mathrm{v}=$ onepage\&q\&f=false. Acesso em: 17 jul. 2018.

MACHADO, Anna Rachell; LOUSADA, Eliane; BARALDI, Glaucimara; ABREUTARDELLI, Lília Santos; TOGNATO, Maria Izabel Rodrigues. Relações entre linguagem e trabalho educacional: novas perspectivas e métodos no quadro do interacionismo sociodiscursivo. Calidoscópio, São Leopoldo, RS, v. 2, n. 2, p. 89-96, jul./dez. 2004. 
ORLANDI, Eni Pulcinelli. O que é linguística. São Paulo: Brasiliense, 2005.

PIPOLLO, Miguel. A Bíblia e o trabalhador. São Paulo: Loyola, 1991.

RICOEUR, Paul. A metáfora viva. São Paulo: Loyola, 2000.

SCHNEUWLY, Bernard. Gêneros e tipos de discurso: considerações psicológicas e ontogenéticas. In: SCHNEUWLY, Bernard; DOLZ, Joaquim. Gêneros orais e escritos na escola. São Paulo: Mercado das Letras, 2004.

SCHOTTROFF, Luise. As parábolas de Jesus. uma nova hermenêutica. São Leopoldo: Sinodal, 2007.

THEISSEN, Gerd; MERZ, Annette. O Jesus histórico: um manual. 2. ed. São Paulo: Loyola, 2004.

VERMES, Geza. Jesus e o mundo do judaísmo. São Paulo: Loyola, 1996.

VYGOTSKY, Lev Semenovich. Pensamento e linguagem. [S./]: Ed. Ridendo Castigat Mores, 2002. E-book. Disponível em:

http://www.ebooksbrasil.org/adobeebook/vigo.pdf. Acesso em: 17 jul. 2018.

VYGOTSKY, Lev Semenovich; LURIA, Alexander Romanovich; LEONTIEV, Aléxis N. Linguagem, desenvolvimento e aprendizagem. 11. ed. São Paulo: Icone, 2010.

ZUURMOND, Rochus. Procurais o Jesus histórico? São Paulo: Loyola, 1998. 